\title{
Transition Time of Ultrasonic Wave as a Tool of Quality Evaluation of Layered Polymer Composites
}

\author{
Małgorzata SZYMICZEK \\ Institute of Theoretical and Applied Mechanics \\ Faculty of Mechanical Engineering \\ Silesian University of Technology \\ Konarskiego 18A, 44-100 Gliwice, Poland; e-mail: malgorzata.szymiczek@polsl.pl \\ (received February 28, 2017; accepted April 7, 2017)
}

\begin{abstract}
Observation of behaviour phenomena of ultrasonic waves in an object allows for quality assessment, identification and location of discontinuity. Physical nature of acoustic processes is based on propagation of mechanical waves constituting a disturbance of equilibrium of the state of material. The acoustic process identified by selected characteristics can be a source of information about state of material, its structure, and properties, which is particularly important for systems exhibiting anisotropy properties, and such are layered polymer composites. They are special materials because their properties depend greatly on the manufacturing technology. Therefore, while conducting acoustic tests which use the influence of elastic properties and homogeneity of material structure for propagation of sound waves the adopted method of measuring characteristics which identifies propagation of ultrasonic wave phenomenon is of particular importance. The aim of the work was quality evaluation of layered polymer composites made by winding and press moulding by the method of echo and C-scan, using head Phased Array. Composites have been tested by thermal and fatigue degradation. Quality evaluation has been made based on the transition time of the ultrasonic wave and the bending strength.
\end{abstract}

Keywords: ultrasonic testing; diagnostics; polymer composites; thermal and ageing-fatigue degradation.

\section{Introduction}

Layered polymer composites are specific group of engineering materials whose properties depend on many factors: both material ones, determining adequate adhesive matrix and reinforcement, and technological ones resulting from capabilities and limitations of the manufacturing method. In the case of materials factor, the quality of a polymer composite is significantly influenced by suitable adhesion of resin to fibre determined by wettability and preparation of fibres (MitTAL, 2009), mutual cooperation of components (RoT, 2001), percentage of reinforcement content, and uniformity of dispersion of modifiers in the resin (Hull, Clyne, 1996). Another problem which determines the quality of composite materials is production technology, which may result in blisters, voids, uncontrolled arrange fibres, local decrease content resin, bad supersaturation, inclusions, or delamination cracks (ADVANI, 2012). Research conducted by BŁAŻEJEWSKI et al. (2005) state that in the case of wound composites the probability of bubbles occurrence is directly proportional to the number of interlaces. Selection of a suitable production technology for composite structure is conditioned by geometry, required properties, and application while minimising economic and social costs (FUCHS, 2008). In the case of technology assisted by vacuum, a potential number of bubbles decrease (ADVANI, 2012). However, regardless of used materials and technology, adequate and of required quality products should be provided.

Due to economic conditions, non-destructive testing uses a range of methods for quality assessment of composites, starting from simplest methods of penetration, tap test to those requiring specialised equipment and instrumentation, e.g. ultrasonic, infrared, acoustic, sherography, computer microtomography etc. (Mallick, 1997; Hufenbach et al., 2011; FAHr, 2014). It should be emphasised that not all of these methods allow identification of discontinuities in volume, and from the point of view of operation and main- 
tenance of this type of construction it is an important problem. Therefore, it seems that ultrasonic methods (MACKIEWICZ, 2005) are a good tool to quality assessment of layered polymer composite.

Application of ultrasound to quality assessment of construction and in particular layered polymer composites is well-known; however, due to the progress of materials engineering and manufacturing technologies, new areas of research are constantly emerging (MALLICK, 2007; FAHR, 2014). Every medium of propagation of ultrasonic waves has its own characteristics that describe behaviour of wave in object, e.g., wave resistance determines the propagation of wave velocity (ŚLIWIŃSKI, 2001).

Due to the application of ultrasound for the diagnosis of layered polymer composites, which are a specific research object, phenomena occurring during the activation of ultrasound wave of material become an important problem. In an attempt to identify discontinuities a change of the amplitude, phase, direction, and intensity of wave should be determined. All of these changes are necessary to describe characteristics of discontinuities and their locations accurately. Ultrasonic assessment of quality is possible thanks to the phenomena of absorption, dissipation, diffraction, interference, refraction, reflection, transformation, penetration, modifying geometry of waves beam, which depend on the size and type of defect (ŚLIWIŃSKI, 2001). Magnitudes of effects of dissipation and diffraction are important information to identify an object's heterogeneity, which is used in ultrasonic inspection.

For example, absorption increases with frequency wave, which increases the propagation velocity of the ultrasonic wave. Weakening of wave, as a result of absorption, is caused in the process of transformation of mechanical energy of waves to dislocation vibrations, electrons, magnetic dipoles, and heat. However, in the case of dissipation, the ultrasonic waves change spread direction of wave as a result of its contact with tested object with uneven, rough surface, or inhomogeneity, which are areas with variable impedance (excluding reflection and refraction). Thus, among important factors which have an impact on absorption we can mention viscosity, conduction, and radiation of heat and molecular relaxation. As far as waves dissipation is concerned, it is inhomogeneity or discontinuity; however, it is difficult to differentiate these two phenomena.

The use of ultrasonic waves for quality assessment of composite materials allows to identify flat, narrowslit discontinuities, even of very small size. Process of detecting discontinuities is initiated by influence of elastic waves (mechanical vibrations with frequencies above $20 \mathrm{kHz}$ ), which, while passing through the tested object, generate impulses being the basis of quality assessment.
Registered signal results are reflection of ultrasonic waves from object with a different density and with the measure being transition time of ultrasonic wave. It is assumed that the propagation velocity of ultrasonic wave in test object is constant, which allows for identification of all dimensions of discontinuity depending on incidence angle of wave. Wave parameters depend on such material properties as density, anisotropy, elastic properties, molecular structure, inhomogeneity, and geometry (Kočıš, FigurA, 1996). For defects of very small size it is recommended to use flaw detector equipped with transducers with as great frequency as possible. The most effective detection of internal defects is obtained if ultrasonic wave is directed to discontinuities at right angles (MACKIEWICZ, 2005).

In the case of conventional echo method, transition time or attenuation of ultrasonic waves can be a diagnostic measure. Propagation velocity of wave is diversified depending on object, content, structure, and type of reinforcing fibres and impact direction of wave (WróBel, PAWLAK, 2006). Maximum velocity is observed in setting direction of fibres, but for fibre reinforced composites only local distribution of fibre content can be determined. The higher fibre content, the higher velocity of propagation of the wave. Attenuation of ultrasonic wave in thickness of material gives a basis for evaluation of adhesion between fibre and matrix. Weak adhesion refers to higher damping.

The use of C-scan, which is imaging the structure in map forms, where the amplitude of echo results from reflection wave which is shown in a variation of colour, creates a development of an echo method, which is a conventional scan technique. Description of differences between the echo method, A-scan, and C-scan techniques is included in (MACKIEwICZ, GórA, 2012).

The aim of the work is quality evaluation of layered polymer composites manufactured by helical winding and press moulding. These composites vary significantly as far as mechanical properties are concerned. Transition time of ultrasonic wave as referred to strength properties was the measure of the quality evaluation of the tested materials. The choice of transition time of ultrasonic wave as diagnostic characteristics was dictated by the possibility of practical application and specific structure of the tested material.

\section{Methodology of research}

There were used two types of composites as research materials. The first one is glass-epoxy pressed in the form of plate having a thickness of $10 \mathrm{~mm} \mathrm{-}$ the sample to heat ageing, $4 \mathrm{~mm}$ - the sample to fatigue degradation (Fig. 1a), and the second glasspolyester wound in the form of a pipe approx. $7 \mathrm{~mm}$ thick (Fig. 1b). The samples from plate and pipes with dimensions $240 \times 20 \mathrm{~mm}$ were cut. 
a)

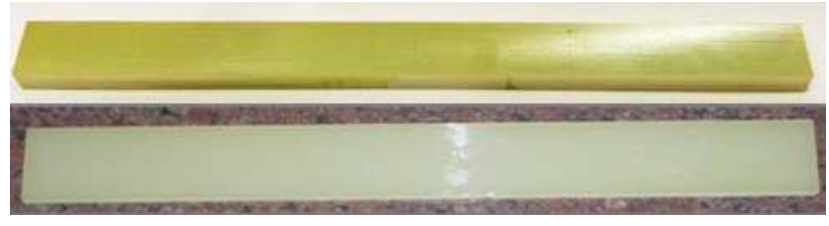

b)

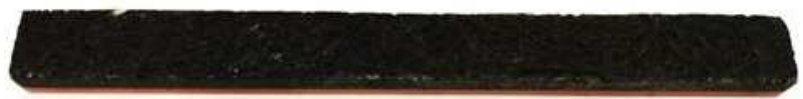

Fig. 1. Test samples: a) glass-epoxy compression moulded, b) glass-polyester wound.

The composites were subjected to ageing and fatigue degradation process, which was conducted in two stages under specific conditions. The first step included thermal degradation and the second involved fatigue. Heat ageing temperature of test composites was at $180^{\circ} \mathrm{C}$, humidity $50 \%$. This process was carried out in the drier with forced air. The samples were positioned in a way that ensures a free air flow - Fig. 2.

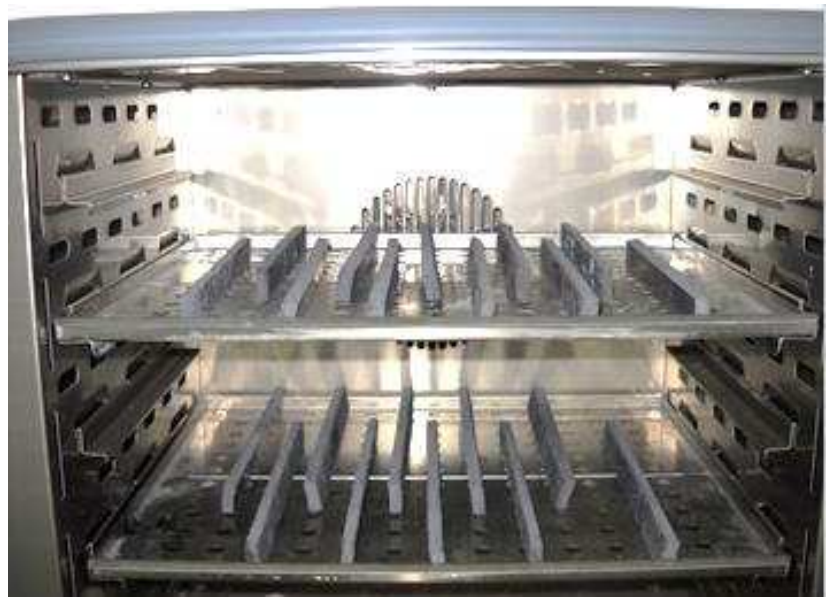

Fig. 2. View of samples of polyester-glass placed in a drier.

Fatigue tests of glass-polyester wound pipes were carried out at $30^{\circ} \mathrm{C}$ in water at the stand and at working conditions described in (SZYMICZEK et al., 2016). The stand allowed for fatigue degradation of pipes with rectangular forced: maximum pressure $8 \mathrm{MPa}$, minimum pressure $1 \mathrm{MPa}$, time of pressure growth $1.5 \mathrm{~s}$, time of maximum pressure $2 \mathrm{~s}$. Epoxy-glass compression moulded composites were tired at ambient temperature at the stand described in work (ROJEK et al., 2007) - Fig. 3. The stand allowed to measure the force for assumed constant deflection. Samples tested with amplitude $3 \mathrm{~mm}$ and frequency $0.8 \mathrm{~Hz}$.

Evaluation of the degree of degradation was made by measuring transition time of ultrasonic wave and strength properties, according to the established pro- a)

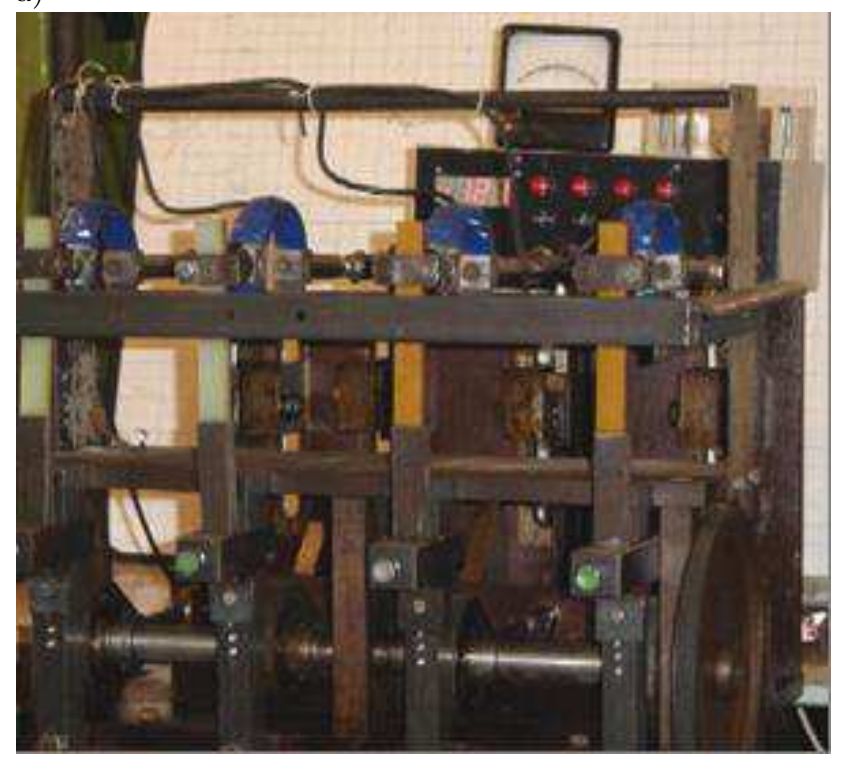

b)

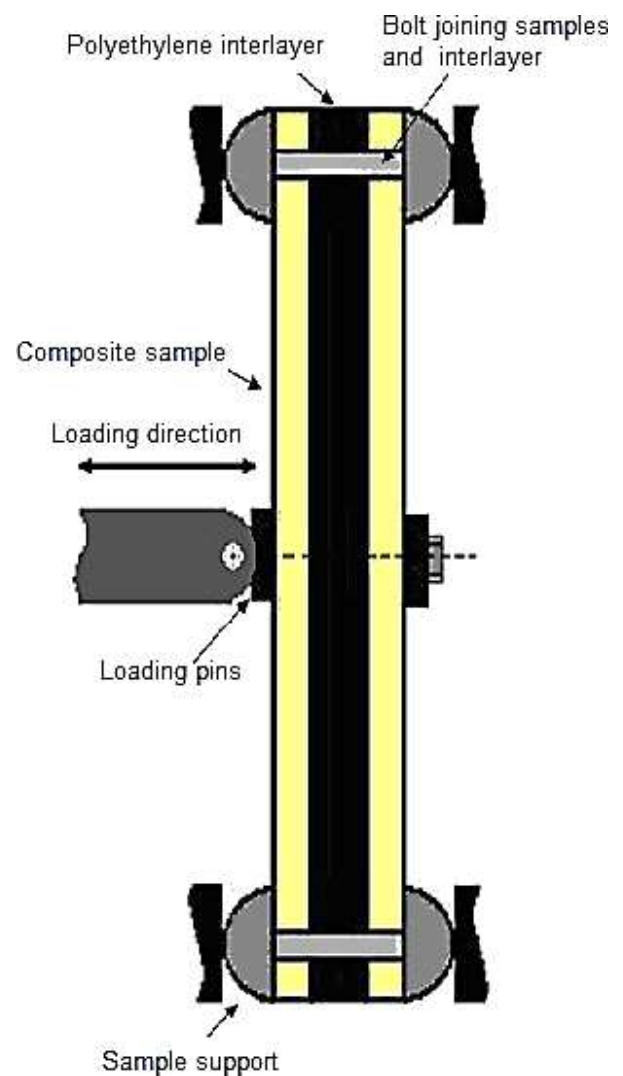

Fig. 3. View of fatigue stand (a) and scheme of loading (b).

gram of research and was compared with reference samples not subjected to degradation processes.

Ultrasonic testing of echo method was conducted on defectoscope UMT 17 cooperating with $2.24 \mathrm{MHz}$ head of Parametrics. The test stand is shown in Fig. 4. In order to improve the contact of ultrasonic head with sample surface, a coupling agent in gel form was used. 


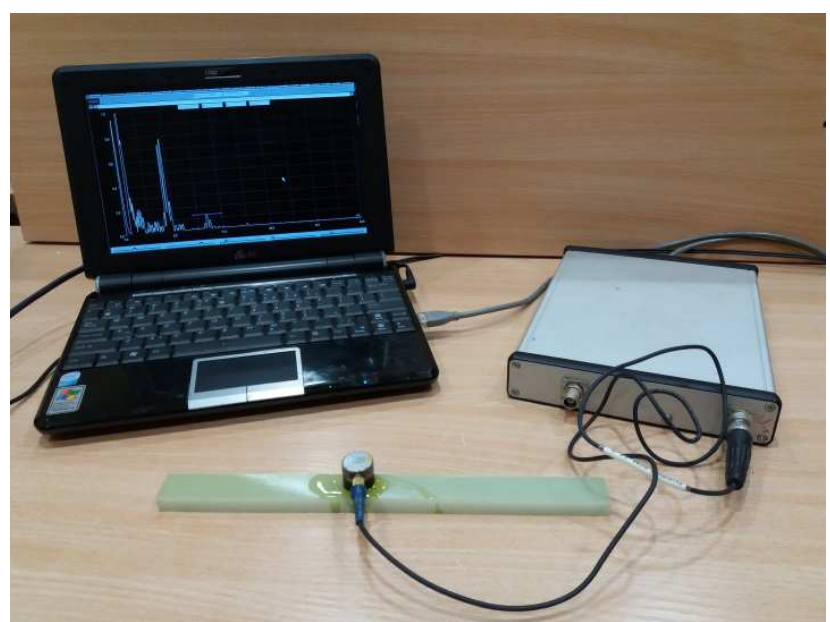

Fig. 4. Stand of ultrasonic testing.

Visualisation of the defect structure was carried by $\mathrm{C}$ - scan method on Phasor XS shared by Testing company, as shown in Fig. 5. The camera was compatible with a head $5 \mathrm{MHz}, 32$ transmitters. The studies were designed to illustrate defect structure of samples which were not subjected to degradation processes.

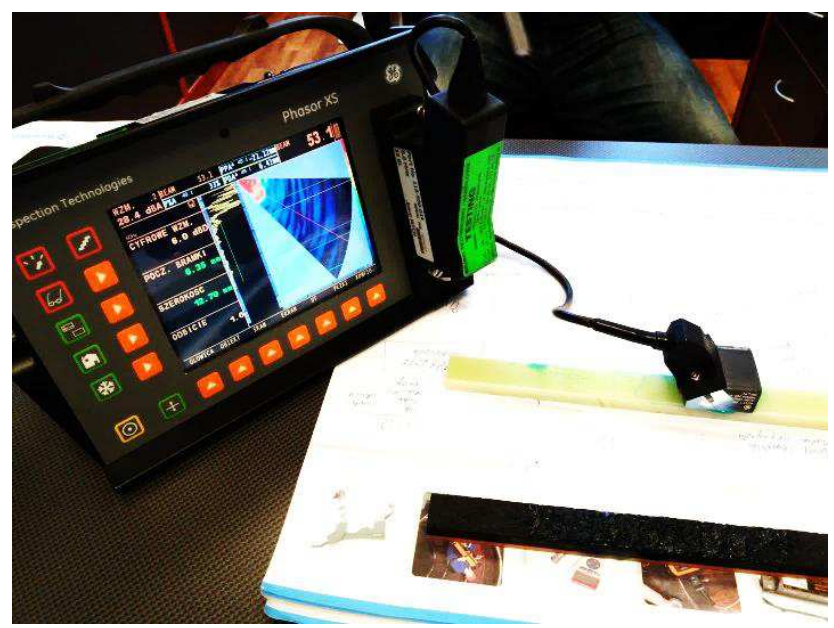

Fig. 5. Stand of C-scan method.

Strength properties of thermally degraded composites were determined in static test of three-point bending according to norm (EN ISO 178). In the same way, specified bending strength of polyester-glass wound composite subjected to ageing-fatigue degradation process was determined. The degree of change in mechanical properties of epoxy-glass compression moulded composites was bending stress $\sigma_{g}$ (ROJEK et al., 2007):

$$
\sigma_{g}=\frac{M_{g}}{W}
$$

where $M_{g}$ is the bending moment $[\mathrm{N} \cdot \mathrm{mm}], W$ is the indicator of bending strength $\left[\mathrm{mm}^{3}\right]$.
In the first stage analysis of characteristics of ultrasonic waves was carried out, allowing for description of changes as a result of thermal, fatigue, and ageingfatigue degradation. Based on the analysis of preliminary results, it was found that the best measure of quality of this composite class is the transition time of ultrasonic wave. The ultrasound wave in wound composites was very dispersed, and therefore it is difficult to observe a second peak of an echo which allows to determine unambiguously the attenuation factor of ultrasonic wave. In compression moulded composites the attenuation coefficient of ultrasonic wave which is related to the structure of the composite material can be defined - Fig. 6 .

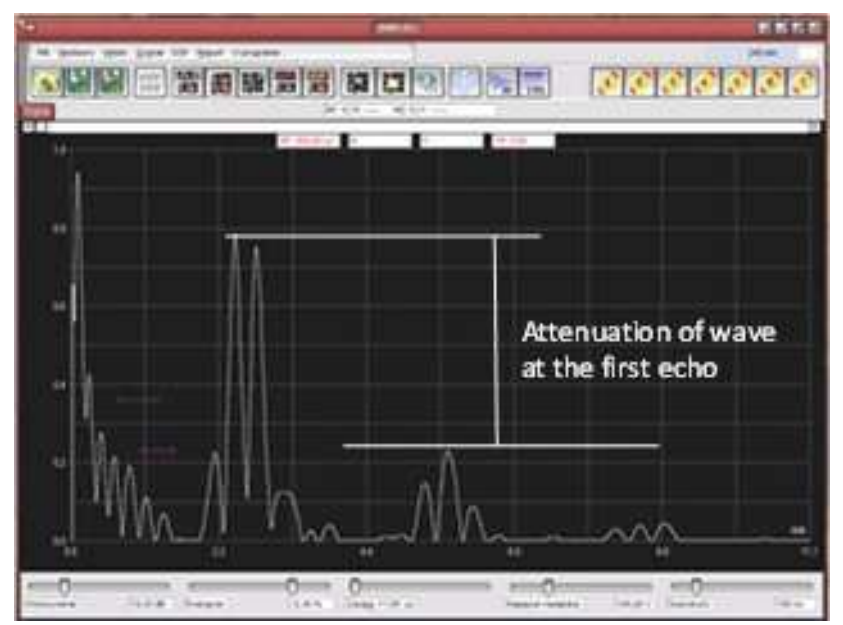

Fig. 6. Spectrum of ultrasonic waves for epoxy-glass compression moulded composite.

During the measurements a large scatter of results could be observed, particularly in the case of wound composites, where there are defects arising from interlaces, winding speed or tension beam, which is connected with manufacturing process. In the compression moulded composites, blisters or voids hardly occur, but there are points of increased resin content with respect to fibres, therefore, a smaller scatter of results occurs.

\section{Results and analysis}

Figure 7 shows the difference in the image of reference samples made by C-scan with phased array, where flaws of various nature can be seen. Figure 7a shows an increase in content of resin relative to fibres observed in compression moulded composite. Figure $7 \mathrm{~b}$ presents blisters and voids resulting from the interlaces geometry, occurring in wound composites. White arrows indicate defects, red ones show the edges of the sample. Figure 8 shows a cross-sectional view of the winding and compression moulded produced composites. These are the cross sections of the samples shown in the ultrasonic images - Fig. 7 . 


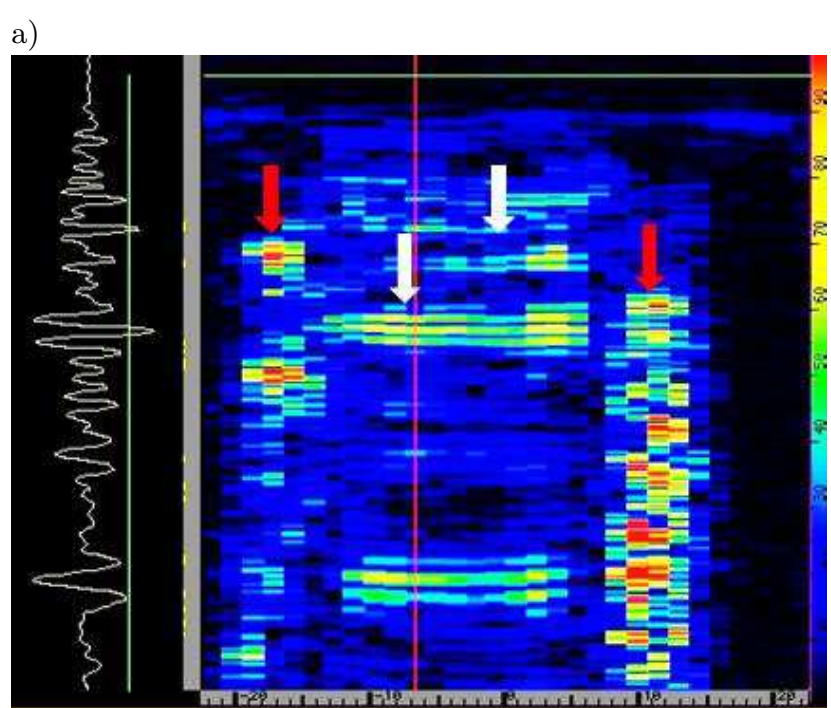

b)

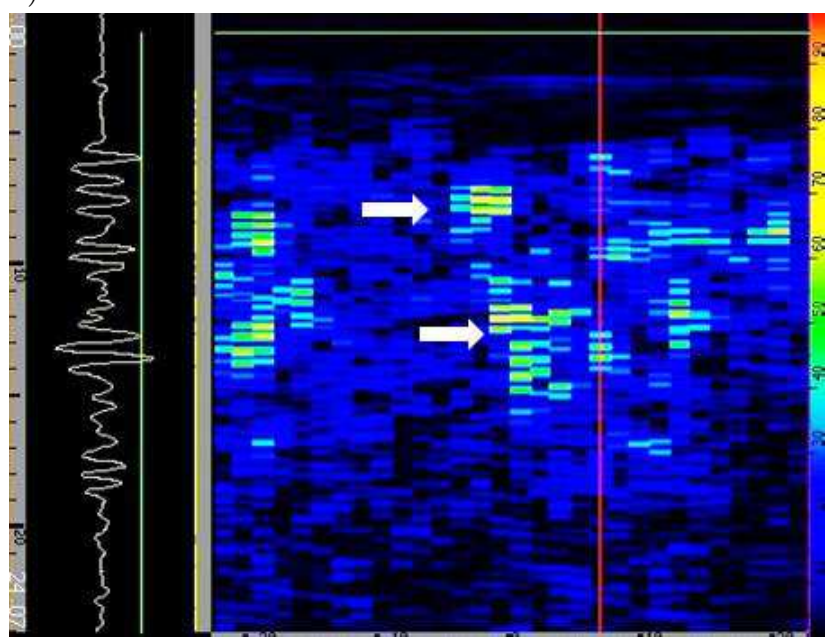

Fig. 7. Defects view in the compression moulded (a) and winding (b) composites by C-scan method.

a)

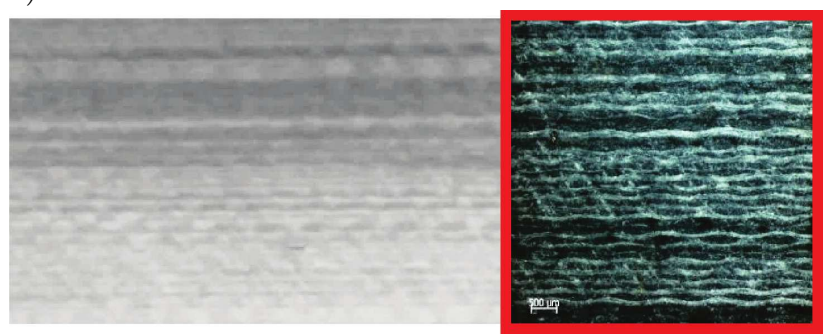

b)

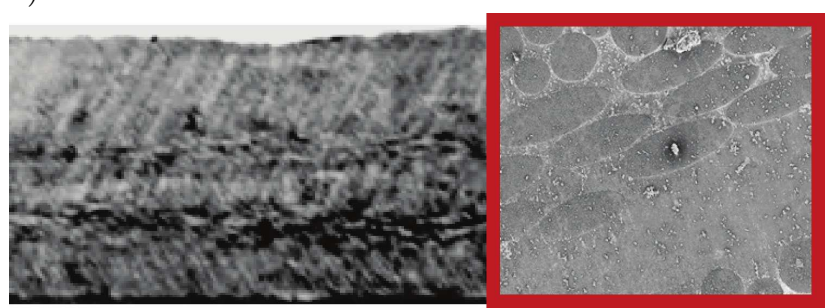

Fig. 8. Defects view in the compression moulded (a) and wound (b) composites.
Figures 9 and 10 show the transition time of ultrasonic wave for thermal ageing samples (in accordance with the procedure described in Sec. 2). The tables in graphs (Figs. 9-15) present the function described by the variability of investigated characteristics during a progressive process of degradation and correlation coefficients. As it can be seen, the defined characteristics of ultrasonic waves for both types of composites decrease with thermal ageing time. For comparison purposes, the functions were approximated with a straight line. The obtained high correlation coefficients indicate a correctly selected function, which allows a quick and easy analysis of changes of transition time of ultrasonic waves. For the wound glass - polyester composite, recorded lower transition times of ultrasonic waves were probably due to properties, geometry, and structure of the test material. There have also been major changes in the transition time, which may be the effect of progressive process of degradation.

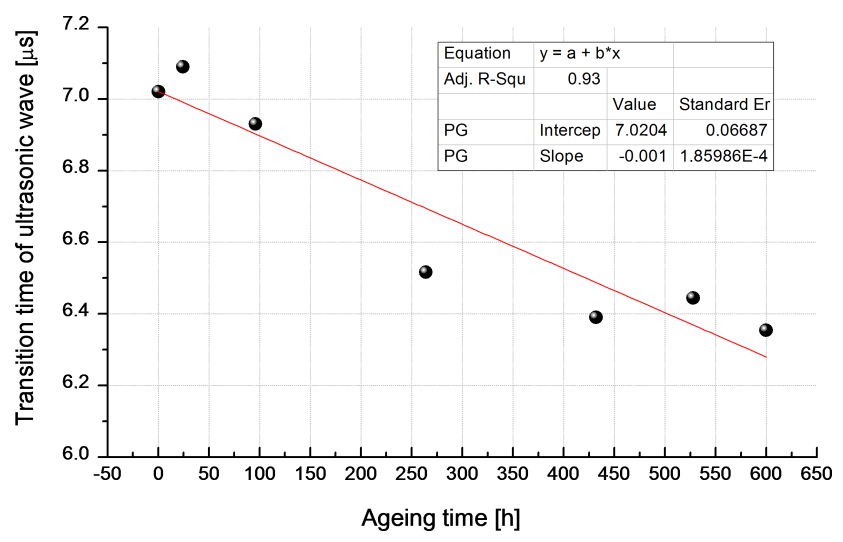

Fig. 9. Transition time of ultrasonic wave as a function of ageing time for polyester-glass wound composites subjected to thermal degradation process.

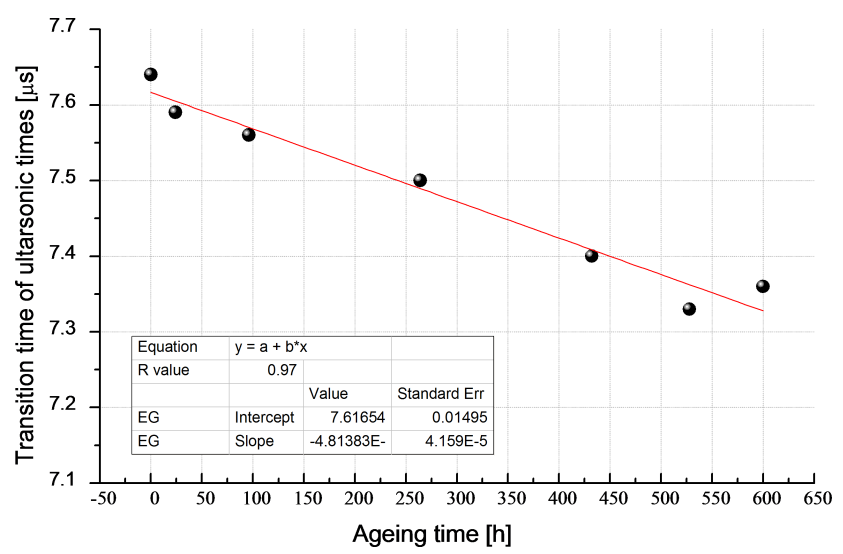

Fig. 10. Transition time of ultrasonic wave as a function of ageing time for epoxy-glass compression moulded composites subjected to thermal degradation process.

Published (SzYMiczeK et al., 2016) research of structure of the polyester-glass wound composite is presented in Fig. 7b - C-scan images and Fig. 8b the macroscopic view of cross-section of samples con- 
firms the occurrence of defects in the form of blisters or discontinuity at the phase boundaries. Dependence of transition time of ultrasonic wave for epoxyglass compression moulded composite shown in Fig. 10 has a much lower change of test characteristics than polyester-glass wound composites. This is the result of the lack of discontinuities (e.g., bubbles), which reflect the ultrasonic wave. Points with increased content of resin (Fig. 7a and 8a) do not have such a significant influence on the transition time of ultrasonic wave as discontinuity, which can be observed in polyester-glass wound composites.

Figures 11 and 12 show the dependence of bending strength as function of ageing time. Decrease in bending strength was observed as the progressive process of thermal degradation, which is confirmed by obtained relationships between transition time of ultrasonic wave and ageing time.

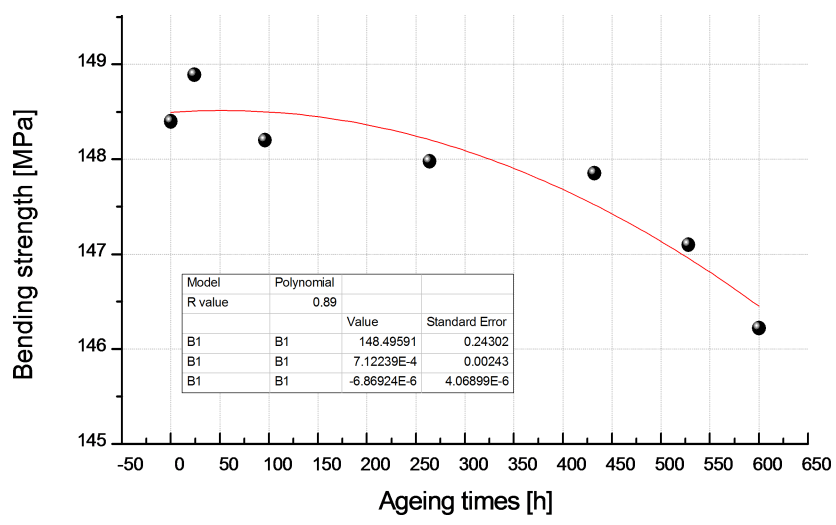

Fig. 11. Bending strength as a function of ageing time for glass-polyester wound composites.

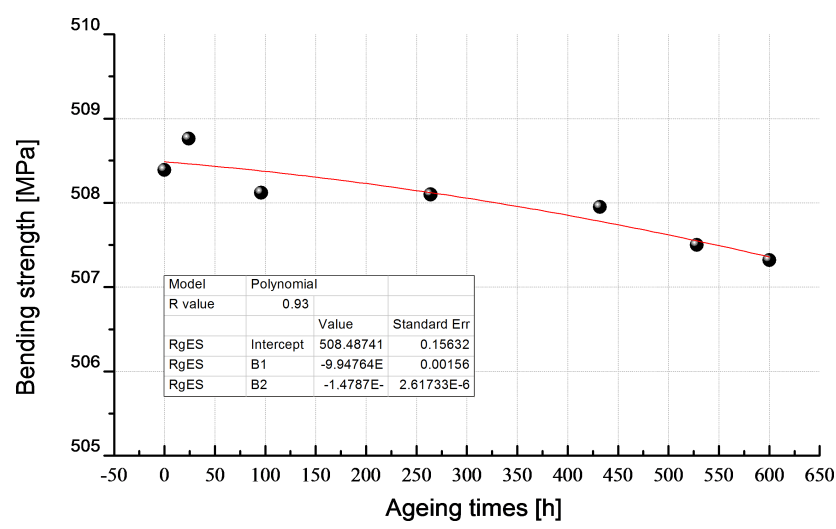

Fig. 12. Bending strength as a function of ageing time for glass-epoxy compression moulded composites.

Figure 13 shows the transition time of an ultrasonic wave as a function of the number of fatigue cycles for glass-polyester wound composites subjected to the process of degradation in water. This is transition time of ultrasonic wave measured for the greatest deformation area, from where the samples were cut for the bending test. The observed large scatter of results

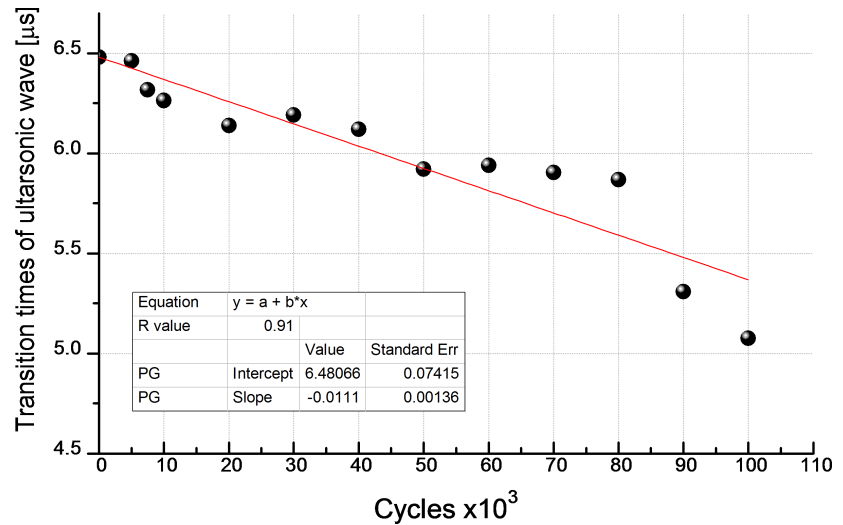

Fig. 13. Transition time of ultrasonic wave as a function of the number of cycles for polyester-glass wound composite subjected to ageing-fatigue degradation process.

is the effect of discontinuities forming on the border of matrix-reinforcement that affects the ultrasonic characteristics. The most common transition time values determined in accordance with Gaussian distribution were taken to determine the dependencies (Fig. 13). The obtained results, as in the case of thermal aging, were approximated by a straight line with the correlation coefficient of 0.91 .

Decrease in the transition time of an ultrasonic wave is the result of appearance of micro- and macroflaws. Micro-cracks lead to delamination as a result of the process of accumulation, and each defect causes the wave scattering. Destruction of pipe samples subjected to fatigue degradation occurs from the inner surface, where the maximum pressure was $8 \mathrm{MPa}$. The wave was reflected from the first discontinuity, hence the observed large spread of the results.

Figure 14 shows the dependence of the transition time of an ultrasonic wave as a function of the number of fatigue cycles for epoxy-glass compression moulded composite. The transition time of an ultrasonic wave increased with the number of fatigue cycles, most prob-

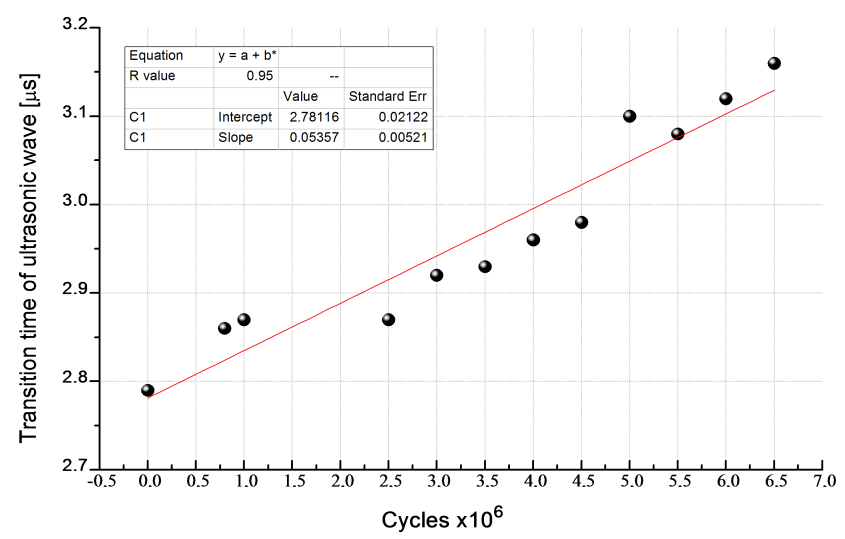

Fig. 14. Transition time of ultrasonic wave as a function of the number of cycles for epoxy-glass compression moulded composite subjected to a fatigue degraded process. 
ably as a result of emerging scattered micro-flaws. During such a process implemented fatigue delamination was not observed. Such image change results from the established research methodology. Bending stress is measured for the deflection arrow.

While comparing the graphs (Figs. 13 and 14) it can be seen that in both cases there are changes of the transition time of an ultrasonic wave, but the nature of the observed changes is different. Figures 15 and 16 illustrate change in the mechanical properties. For the polyester-glass wound composite it is bending strength - Fig. 15, and for the epoxy-glass compression moulded composites it is bending stress determined during the fatigue degradation process in the central area of the sample - Fig. 16 (ROJEK et al., 2007).

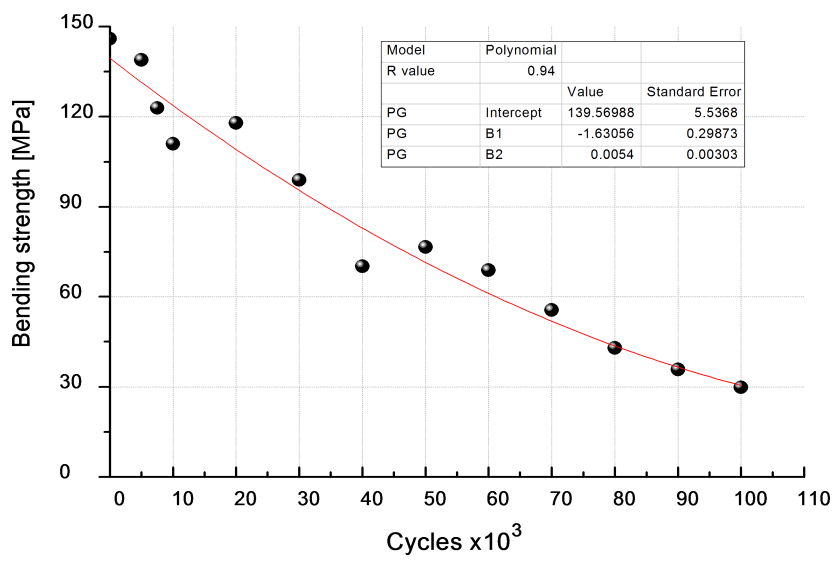

Fig. 15. Bending strength as a function of the number of fatigue cycles for polyester-glass wound composites.

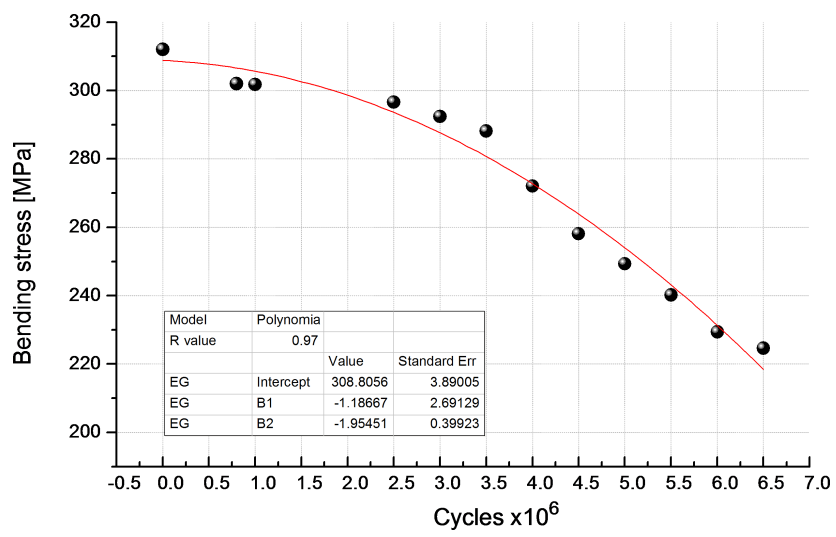

Fig. 16. Bending stress as a function of the number of fatigue cycles for epoxy-glass compression moulded composites.

As it can be seen in both, bending strength and bending stress decrease with the number of fatigue cycles, but the nature of these changes seems to be different due to properties of the tested composites and loads process. When comparing the strength characteristics with the transition time of ultrasonic waves, a different mechanism of destruction can be concluded. On the basis of the measure of transition time of ul- trasonic wave, state of the material can be determined, assuming that reference characteristics of the material not subjected to thermal or ageing-fatigue degradation process is known.

\section{Conclusions}

On the basis of the carried out research it can be concluded that:

1) Measurement of transition time of ultrasonic wave enables the quality evaluation of composite material at a given exploitation stage. Monitoring and identification of progressive changes in the polymer layered composite allow for safe exploitation.

2) Research of ultrasonic and mechanical characteristics depends not only on material parameters but also on the technology of a composite, which determines the quality of composite material subjected to degradation processes.

3) The nature of the observed changes during a thermal degradation for the tested composites is similar. The observed changes of the transition time of ultrasonic waves during fatigue degradation of tested composites may be due to type of flaws (dispersion micro-defect and macro-defects) and research methodology used. Decreased mechanical properties in the progressive process of fatigue degradation are result of structural defects.

4) Transition time of ultrasonic waves is an adequate measure of the progressive degradation process for composite materials. Nevertheless, it is important to determine initial properties of research characteristics, taking into account manufacturing technology, and for the layered polymer composite it is an important parameter for the correct interpretation of the results.

\section{References}

1. Advani S., Hsiao K.T. (2012), Manufacturing techniques for polymer matrix composites (PMCs), Woodhead Publishing, Cambridge.

2. BŁażejewski W., Hufenbach W., Czulak A., Bozнm R. (2005), Preparation and testing of composite tubular samples of glass fiber reinforced [in Polish: Wytwarzanie $i$ badanie kompozytowych próbek rurowych wzmocnionych włóknem szklanym], Kompozyty, 5, 4, 67-71.

3. FAhr A. (2014), Aeronautical applications of nondestructive testing, DStech Publication, Lancaster.

4. Ferreira J.M., Pires J.T.B., Costa J.D., ErrajHi O.A., Richardson M. (2007), Fatigue damage and environment interaction of polyester aluminized glass fiber composites, Composite Structure, 78, 3, 397-401.

5. Fuchs E.R.H., Field F.R., Roth R., Kirchain R.E. (2008), Strategic materials selection in the automobile 
body: economic opportunities for polymer composite design, Composites Science and Technology, 68, 19892002 .

6. Hufenbach W., Gude M., Czulak A., Gąsior P., Kretschmann M. (2011), Manufacturing and pressure tests of braided vessels with integrated optical fiber sensors, Plastics Processing, 6, 454-459.

7. Hull D., Clyne T.W. (1996), An introduction to composite materials, Cambridge University Press, Cambrige.

8. KočIš S., Figura Z. (1996), Ultrasonic Measurements and Technologies, Chapman \& Hall, London.

9. MaCKiewicz S., Góra G. (2005), Ultrasonic testing of composite structures in the aerospace industry [in Polish: Ultradźwiękowe badania konstrukcji kompozytowych w przemyśle lotniczym], Procceding of 11th Seminar "Non Destructive Test Methods", Zakopane.

10. Mackiewicz S., Góra G. (2012), Ultrasonic testing of carbon laminate Phased Array technique [in Polish: Ultradźwiękowe badania laminatów weglowych technika Phased Array], Procceding of 13th Seminar "Non Destructive Test Methods", Zakopane.

11. Mallick P.K. (1997), Nondestructive tests. Composites Engineering Handbook, New York.
12. Mittal K.L. (2009), Silanes and Other Coupling Agents, VSP, Boston.

13. Rojek M., Stabik J., Sokóє S. (2007), Fatigue and ultrasonic testing of epoxy-glass composites, Journal Achievements in Materials and Manufacturing Engineering, 20, 1-2, 183-186.

14. Rot K., Huskić M., Makarovič M., Mlakar T., Z̆IGON M. (2001), Interfacial effects in glass fibre composites as a function of unsaturated polyester resin composition, Composites Part A: Applied Science and Manufacturing, 32, 3, 511-516.

15. ŚliwińsKi A. (2001), Ultrasounds and their applications [in Polish: Ultradźwięki i ich zastosowania] (2nd ed), WNT, Warszawa.

16. Szymiczek M., Rojek M., Wróbel G. (2016), The influence of the ageing-fatigue degradation on the mechanical properties of glass-reinforced composites, Polish Journal of Chemical Technology, 18, 1, 113-119.

17. WróBel G., PAWlaK S. (2006), Ultrasonic evaluation of the fibre content in glass/epoxy composites, Journal of Achievements in Materials and Manufacturing Engineering, 18, 1-2, 187-190. 